GRANADO, Juliete Ruana Madra; BONISSONI, Natammy Luana. O direito ambiental, o princípio da prevenção e o acesso à Avaliação Ambiental Estratégica. Revista Eletrônica Direito e Política, Programa de Pós-Graduação Stricto Sensu em Ciência Jurídica da UNIVALI, Itajaí, v.10, n.1, edição especial de 2015. Disponível em: www.univali.br/direitoepolitica - ISSN 1980-7791.

\title{
O DIREITO AMBIENTAL, O PRINCÍPIO DA PREVENÇÃO E O ACESSO À AVALIAÇÃO AMBIENTAL ESTRATÉGICA
}

\author{
THE ENVIRONMENTAL LAW, THE PRINCIPLE OF PREVENTION AND ACCESS \\ TO STRATEGIC ENVIRONMENTAL ASSESSMENT
}

\author{
Juliete Ruana Mafra Granado ${ }^{1}$ \\ Natammy Luana Bonissoni ${ }^{2}$
}

SUMÁRIO: Introdução; 1 . Aspectos gerais da construção do Direito Ambiental; 2. Lo estrato preventivo: os aportes do princípio da prevenção na consecução da proteção ambiental; 3. A instrumentalização eficaz do princípio preventivo: um recurso para a Avaliação Ambiental Estratégica; Considerações Finais; Referências das Fontes Citadas.

RESUMO: A pesquisa teve por objeto analisar a importância do princípio à prevenção ao meio ambiente, observando a sua aplicabilidade mediante o instrumento da Avaliação Ambiental Estratégica- AAE. Assim, especificou-se como objetivo observar o desapontamento do pressuposto a prevenção ambiental e compreender o instituto da Avaliação Ambiental Estratégica, verificando-se a possibilidade deste instituto servir como ferramenta para garantir a sua efetividade. Para alcançar tal enfoque, a pesquisa foi dividida em três momentos: no primeiro, realizou-se uma análise sobre a construção histórica do meio ambiente e sua evolução como direito fundamental; na segunda etapa, estudou-se a fase preventiva e os aportes do princípio da prevenção na consecução da proteção ambiental; já na terceira fase, curial se mostrou entender a instrumentalização eficaz do princípio preventivo através da Avaliação Ambiental Estratégica, entendendo os elementos e características que compõem o instituto. Considera-se, portanto, que a Avaliação Ambiental Estratégica consiste em mecanismo de análise e avaliação dos níveis mais

\footnotetext{
${ }^{1}$ Mestranda em Ciência Jurídica no Programa de Pós-Graduação Stricto Sensu da Universidade do Vale do Itajaí. Advogada. Bolsista do PROSUP - CAPES. E-mail: julietemafra@univali.br. Bacharel pelo Curso de Direito da Universidade do Vale do Itajaí.

2 Mestranda em Ciência Jurídica no Programa de Pós-Graduação Stricto Sensu da Universidade do Vale do Itajaí. Advogada. Bolsista do PROSUP - CAPES. E-mail: natammy@univali.br. Bacharel pelo Curso de Direito da Universidade do Vale do Itajaí.
} 
GRANADO, Juliete Ruana Madra; BONISSONI, Natammy Luana. O direito ambiental, o princípio da prevenção e o acesso à Avaliação Ambiental Estratégica. Revista Eletrônica Direito e Política, Programa de Pós-Graduação Stricto Sensu em Ciência Jurídica da UNIVALI, Itajaí, v.10, n.1, edição especial de 2015. Disponível em: www.univali.br/direitoepolitica - ISSN 1980-7791.

estratégicos para a tomada de decisões políticas, planos e programas contra as ações com consequentes impactos ambientais, para o fim de prevenir a ocorrência de danos, viabilizandoo crescimento ao passo que assegura a proteção ambiental. É forte instrumento dando calço à consecução do desenvolvimento sustentável. Quanto à Metodologia, foi utilizada a base lógica Indutiva por meio da pesquisa bibliográfica.

Palavras-Chave: Direito Ambiental. Princípio da Prevenção. Avaliação Ambiental Estratégica.

ABSTRACT: This research aimed to analyze the importance of the prevention principle of the environment, noting its applicability through the instrument of theStrategic Environmental Assessment. Thus, it was stated as a goal observe thedisappointmentof the assumption to the environmental prevention and comprehendthe Institute of Strategic Environmental Assessment, verifying the possibility of the institute to serve as a tool to ensure their effectiveness. To achieve this focus, the research was divided into three stages: the first one conducted an analysis on the historical analysis of the environment and its evolution as a fundamental right; in the second stage, it was studied the preventive phase and the contributions of the prevention principle in achieving environmental protection; already in the third stage, it became essential understand the effective exploitation of the preventive principle through the Strategic Environmental Assessment, understanding the elements and characteristics that make up the institute. Therefore it is considered that Strategic Environmental Assessment consists on a mechanism of analysis and evaluation of the most strategic levels for policy decisions, plans and programs against the actions with consequent environmental impacts, to prevent the occurrence of damage, enabling growth while ensuring environmental protection. It's a solid instrument that assists in achieving sustainable development. Regarding the methodology, the inductive method was used by the bibliographic research.

Keywords: Environmental Law. Prevention Principle. Strategic Environmental Assessment.

\section{INTRODUÇÃo}

Em vista do antropocentrismo, o homem, com sua racionalidade e força dominante, sempre atuou com exploração e governo sobre a natureza, despreocupado com o respaldo de proteger um meio ambiente sadio e ecologicamente equilibrado.

Neste ínterim, a ideia de proteção e prevenção do ambiente que o circunda não 
GRANADO, Juliete Ruana Madra; BONISSONI, Natammy Luana. O direito ambiental, o princípio da prevenção e o acesso à Avaliação Ambiental Estratégica. Revista Eletrônica Direito e Política, Programa de Pós-Graduação Stricto Sensu em Ciência Jurídica da UNIVALI, Itajaí, v.10, n.1, edição especial de 2015. Disponível em: www.univali.br/direitoepolitica - ISSN 1980-7791.

fez parte da tradicional cultura humana, ao contrário, explorar o ecossistema é o que condiz com sua essência dominante.

Ao longo de séculos, explorando os recursos naturais, foi tardiamente que o homem tomou por si os primeiros ideais de receio sobre a possibilidade do que viria a ocorrer num futuro próximo.

O alerta global sobre a exploração exacerbada e o consumo pelo consumo só despontou com consideração após a humanidade sofrer as primeiras consequências do movimento degradante.

Precisou de que a natureza mostrasse os danos ambientais e desequilíbrios afetos para que se tomasse ciência da situação alarmante, ou do que a humanidade já detinha conhecimento, mas preferia fingir desconhecer, estando inerte sobre a real face da crise ambiental.

A conduta humana negligente é que deu decorrência à crise ambiental, fato que fez com que a proteção do meio ambiente passasse a encontrar problemática de interesse social e, por conseguinte, aplicabilidade jurídica. Em especial, o tema tomou pertinência de suma importância, tornando-se pressuposto constitucional em vigor.

Neste sentido, despontou o ideal de prevenção ambiental e a imprescindibilidade de resguarde ambiental qualitativo, a fim de garantir a pureza do ecossistema na exploração consciente das gerações presentes em favor da manutenção da qualidade de vida para as gerações futuras.

Desta forma, este artigo tem por questão analisar como a prevenção ambiental encontra pertinência jurídica, demonstrando que a Avaliação Ambiental Estratégica - AAE consiste em instrumento que possibilita a consecução deste instituto, encontrando-se, ainda, como mecanismo para o alcance do desenvolvimento sustentável.

É crescente a consciência em diversos países e instituições internacionais sobre importância do mecanismo da Avaliação Ambiental Estratégica - AAE, posto que ele tem sido instrumento inserido no ordenamento jurídico internacionais, isto 
GRANADO, Juliete Ruana Madra; BONISSONI, Natammy Luana. O direito ambiental, o princípio da prevenção e o acesso à Avaliação Ambiental Estratégica. Revista Eletrônica Direito e Política, Programa de Pós-Graduação Stricto Sensu em Ciência Jurídica da UNIVALI, Itajaí, v.10, n.1, edição especial de 2015. Disponível em: www.univali.br/direitoepolitica - ISSN 1980-7791.

para auxiliar na garantia a prevenção ambiental.

Destarte, o objeto da presente pesquisa é a análise da aplicação do princípio da prevenção ambiental frente ao acesso a Avaliação Ambiental Estratégica. O Objetivo Geral é o de compreender aplicabilidade do princípio da prevenção na proteção ao meio ambiente, efetivando-se através do instrumento da AAE. Os Objetivos Específicos são: a) traçar uma linha de raciocínio entre Avaliação Ambiental Estratégica e o princípio da prevenção ambiental; b) compreender a importância da manutenção do meio ambiente; c) entender acrise ambiental vivenciada nos dias atuais; d) identificar que Avaliação Ambiental Estratégica pode servir como mecanismo para a proteção ambiental, através da prevenção e, ainda, no auxílio a consecução do desenvolvimento sustentável.

O artigo está dividido emtrês momentos: no primeiro se faz uma análise sobre os aspectos gerais da construção do Direito Ambiental; o segundo faz considerações acerca do despontamento da fase preventiva e os aportes do princípio da prevenção na consecução da proteção ambiental; por fim, o terceiro trata da instrumentalização eficaz do princípio preventivo, isto mediante o instrumento da Avaliação Ambiental Estratégica.

Quanto à Metodologia, o relato dos resultados será composto na base lógica Indutiva $^{3}$. Nas diversas fases da Pesquisa, serão utilizadas as Técnicas do Referente $^{4}$, da Categoria ${ }^{5}$, do Conceito Operacional ${ }^{6}$ e da Pesquisa Bibliográfica ${ }^{7}$.

3 "[...] pesquisar e identificar as partes de um fenômeno e colecioná-las de modo a ter uma percepção ou conclusão geral [...]". PASOLD, Cesar Luis. Metodologia da pesquisa jurídica: Teoria e prática. 11 ed. Florianópolis: Conceito editorial/Milleniuum, 2008. p. 86.

4 "[...] explicitação prévia do(s) motivo(s), do(s) objetivo(s) e do produto desejado, delimitando o alcance temático e de abordagem para a atividade intelectual, especialmente para uma pesquisa." PASOLD, Cesar Luis. Metodologia da pesquisa jurídica: Teoria e prática. p. 53.

5 "[...] palavra ou expressão estratégica à elaboração e/ou à expressão de uma idéia." PASOLD, Cesar Luis. Metodologia da pesquisa jurídica: Teoria e prática. p. 25.

6 " $[. .$.$] uma definição para uma palavra ou expressão, com o desejo de que tal definição seja$ aceita para os efeitos das idéias que expomos [...]". PASOLD, Cesar Luis. Metodologia da pesquisa jurídica: Teoria e prática. p. 37.

7 "Técnica de investigação em livros, repertórios jurisprudenciais e coletâneas legais. PASOLD, Cesar Luis. Metodologia da pesquisa jurídica: Teoria e prática. p. 209. 
GRANADO, Juliete Ruana Madra; BONISSONI, Natammy Luana. O direito ambiental, o princípio da prevenção e o acesso à Avaliação Ambiental Estratégica. Revista Eletrônica Direito e Política, Programa de Pós-Graduação Stricto Sensu em Ciência Jurídica da UNIVALI, Itajaí, v.10, n.1, edição especial de 2015. Disponível em: www.univali.br/direitoepolitica - ISSN 1980-7791.

\section{ASPECTOS GERAIS DA CONSTRUÇÃO DO DIREITO AMBIENTAL}

Como fruto de dimensões históricas e culturais, o meio ambiente, nos moldes do artigo $3^{0}$ da Lei $6938 / 81^{8}$ é definido como o "conjunto de condições, leis, influências e interações de ordem física, química e biológica, que permite, abriga e rege a vida em todas as suas formas".

Nestes moldes, observa-se que o Meio Ambiente é apresentado como um direito humano fundamental, configurado como direito de todos, bem de uso comum do povo e indispensável à qualidade de vida saudável ${ }^{9}$.

Ocorre que a proteção ao meio ambiente sadio e equilibrado, em respaldo a sua conservação ecológica, consiste em direito fundamental que, para encontrar eficácia, precisa adotar um modelo de desenvolvimento econômico diferente, que inclua em seus projetos, a variante de preservação ambiental, analisando os impactos que serão acarretados à natureza com a escolha de uma ou outra atividade, isto consiste na concretização do princípio do desenvolvimento sustentável estratégico ${ }^{10}$.

Para tanto, com o passar dos tempos, todos estes conjuntos de condições de leis e interações que governam a vida em todas as formas passaram por transformações em detrimento à continuidade da espécie humana, ou até mesmo, em favor de sua comodidade.

Desde o surgimento da agricultura, o qual ocasionou a criação de um meio ambiente artificial propício para o cultivo de plantas e gado, iniciou-se o domínio do homem sobre a natureza, sem se preocupar com o respaldo da proteção do ambiente sadio e ecologicamente equilibrado. Desde então, a proteção ambiental

\footnotetext{
${ }^{8}$ Disponível em http://www.planalto.gov.br/ccivil_03/leis/l6938.htm. Acesso em27/11/13.

${ }^{9}$ ANTUNES, Paulo Bessa. Direito Ambiental. 8. ed. Rio de Janeiro: Lumen Juris, 2005. p. 19 20.

${ }^{10}$ SOARES, G. F. S. Direito internacional do meio ambiente: emergência, obrigações e responsabilidades. São Paulo: Atlas, 2001.p. 175-176.
} 
GRANADO, Juliete Ruana Madra; BONISSONI, Natammy Luana. O direito ambiental, o princípio da prevenção e o acesso à Avaliação Ambiental Estratégica. Revista Eletrônica Direito e Política, Programa de Pós-Graduação Stricto Sensu em Ciência Jurídica da UNIVALI, Itajaí, v.10, n.1, edição especial de 2015. Disponível em: www.univali.br/direitoepolitica - ISSN 1980-7791.

deixa aparentar um interesse menor ou insignificante, e começa a alcançar lugares de privilégios nos atuais ordenamentos jurídicos. ${ }^{11}$

Com o crescente interesse por tais temas, Fritjof Capra citou em sua obra "A Teia da Vida" acercada importância de não estudar todas estas problemáticas atuais de modo isolado, tendo em vista tais assuntos serem considerados como problemas sistêmicos, totalmente interligados e interdependentes. De mesmo modo, o físico austríaco expõe a necessidade do surgimento de um novo paradigma fundamentado na concepção do mundo como um todo integrado, e "não como uma coleção de partes dissociadas"12.

Com o "start" da crise ecológica, diversas mobilizações civis surgiram com a finalidade de atuar em defesa da natureza, o qual resultou em valores ainda não vistos antes e práticas de abrangência comunitária. Com isso, nasce o movimento ambientalista na tentativa de resolver as distorções provocadas pela crise ecológica tendo em vista o Estado não ter sido competente na prevenção e proteção dos mesmos. ${ }^{13}$

A instantânea urbanização, fruto da Revolução Industrial, oportunizou profundas e diversas alterações no ambiente natural. Reinaldo Dias relata ${ }^{14}$ :

Ainda nos primórdios da industrialização, um economista inglês, Thomas Robert Malthus (1766 - 1834), publicou um trabalho denominado Ensaio sobre a população: como afeta o futuro progresso da humnanidade (1798), onde sistematizava um conjunto de preocupações que apontava para os problemas decorrentes do aumento populacional e para a possibilidade de esgotamento dos recursos naturais e seus reflexos no crescimento econômico. Dando destaque ao crescimento populacional, afirmava que "o poder da

${ }^{11}$ BONISSONI, Natammy. A internacionalização da proteção dos direitos humanos e da proteção ambiental. In: SOUZA, Maria Claudia Silva Antunes de Souza; ARMADA, Charles Alexandre Souza. Org(s).Teoria Jurídica e Transnacionalidade. Itajaí: UNIVALI, 2014. p. 20-36. Disponível em file:///C:/Users/User/Downloads/Free_851f3382-7fb7-498d-be73-1077dfdf56b2.pdf. Acesso em $31 / 08 / 2014$.

12 CAPRA, Fritjof. A Teia da vida. São Paulo: CULTRIX, 1996, p. 16

13 SARLET, Ingo; FENSTERSEIFER, Tiago. Direito constitucional ambiental. 3. ed. São Paulo: Revista dos Tribunais, 2013, p. 35.

${ }^{14}$ DIAS, Reinaldo. Gestão Ambiental - Responsabilidade Social e Sustentabilidade. São Paulo: Atlas, 2007. 
GRANADO, Juliete Ruana Madra; BONISSONI, Natammy Luana. O direito ambiental, o princípio da prevenção e o acesso à Avaliação Ambiental Estratégica. Revista Eletrônica Direito e Política, Programa de Pós-Graduação Stricto Sensu em Ciência Jurídica da UNIVALI, Itajaí, v.10, n.1, edição especial de 2015. Disponível em: www.univali.br/direitoepolitica - ISSN 1980-7791.

população é infinitamente maior que o da terra para produzir a subsistência do homem".

Em razão da negligente conduta humana, majorada pela Revolução Industrial, iniciou-se a crise ambiental, trazendo também a possibilidade da proteção ao meio ambiente ser tratada com um maior cuidado e, consequentemente, aplicabilidade jurídica, inclusive, tornando-a pressuposto constitucional vigente em diversas Constituições. ${ }^{15}$

Para Canotilho e Morato Leite ${ }^{16}$ :

[...] a proteção ambiental deixa, definitivamente, de ser um interesse menor ou acidental no ordenamento, afastando-se dos tempos em que, quando muito, era objeto de acaloradas, mas juridicamente estéreis, discussões no terreno não jurígeno das ciências naturais ou literatura.

A Conferência de Estocolmo sobre o Meio Ambiente, realizada em 1972, demonstrou vários exemplos de degradação ambiental, ressaltando a pureza da água e do ar. No Brasil, os primeiros exemplos de proteção ao meio ambiente marcaram o século XVII, apontando a proteção do pau-brasil como propriedade real. Um pouco mais a frente, nas décadas seguintes, foram assinadas as primeiras Cartas propendendo ao amparo e conservação das florestas. ${ }^{17}$

Com o crescente avanço do processo de desconstituição da soberania em nome da economia de mercado neoliberal, percebe-se cada vez mais a falta de ética, bem como a ausência de capacidade normativa para regular o mercado. ${ }^{18}$ Recordando Kelsen, compreende-se a necessidade de existência da norma

${ }^{15}$ BONISSONI, Natammy. A internacionalização da proteção dos direitos humanos e da proteção ambiental. In: SOUZA, Maria Claudia Silva Antunes de Souza; ARMADA, Charles Alexandre Souza. Org(s). Teoria Jurídica e Transnacionalidade. Itajaí: UNIVALI, 2014. p. 20-36. Disponível em file:///C:/Users/User/Downloads/Free_851f3382-7fb7-498d-be73-1077dfdf56b2.pdf. Acesso em $31 / 08 / 2014$.

16 CANOTILHO, José Joaquim Gomes; LEITE, José Rubens Morato Leite. Direito ambiental constitucional brasileiro. São Paulo: Saraiva, 2010, p. 93.

17 SILVA, Geraldo Eulálio do Nascimento e. Direito ambiental internacional. Rio de Janeiro: Thex Ed. 2002, p. 27.

${ }^{18}$ BONISSONI, Natammy. A internacionalização da proteção dos direitos humanos e da proteção ambiental. In: SOUZA, Maria Claudia Silva Antunes de Souza; ARMADA, Charles Alexandre Souza. Org(s). Teoria Jurídica e Transnacionalidade. Itajaí: UNIVALI, 2014. p. 20-36. Disponível em file:///C:/Users/User/Downloads/Free_851f3382-7fb7-498d-be73-1077dfdf56b2.pdf. Acesso em $31 / 08 / 2014$. 
GRANADO, Juliete Ruana Madra; BONISSONI, Natammy Luana. O direito ambiental, o princípio da prevenção e o acesso à Avaliação Ambiental Estratégica. Revista Eletrônica Direito e Política, Programa de Pós-Graduação Stricto Sensu em Ciência Jurídica da UNIVALI, Itajaí, v.10, n.1, edição especial de 2015. Disponível em: www.univali.br/direitoepolitica - ISSN 1980-7791.

fundamental hipotética como fruto de um Estado abalizado na Constituição soberana ${ }^{19}$.

Percebe-se então a compreensão da existência da crise ambiental, especialmente após a constatação de que as condições tecnológicas e industriais juntamente com as formas de organização e gestões econômicas tão presentes na sociedade contemporânea conflitam com a qualidade de vida ${ }^{20}$.

A Constituição da República Federativa do Brasil prevê em seu art. 225 o termo "meio ambiente ecologicamente equilibrado", com a finalidade de evitar a possível ideia de um meio ambiente equilibrado sem qualificação ecológica, ou seja, sem relações essenciais dos seres vivos entre si e deles com o meio. Portanto, "conservação ecológica" consiste na "gestão da utilização da biosfera pelo ser humano, de tal sorte que produza maior benefício sustentado para gerações atuais, mas que mantenha sua potencialidade para satisfazer às necessidades e às aspirações das gerações futuras"21.

Em linhas gerais, pode-se perceber que os modelos constitucionais contemporâneos tem equiparado a proteção ambiental como um direito fundamental. Logo, acrescenta Canotilho ${ }^{22}$ e Morato Leite:

Pela via da norma constitucional, o meio ambiente é alçado ao ponto máximo do ordenamento, privilégio que outros valores sociais relevantes só depois de décadas, ou mesmo séculos, logram conquistar.

Com a intenção de se efetivar a tutela ao meio ambiente e corroborar o desenvolvimento econômico e social para próximas gerações, foi legitimada na Eco 92 a importância do ambiente sustentável, considerando-o duradouramente

\footnotetext{
${ }^{19}$ LEITE, José Rubens Morato; FILHO, Ney de Barros Mello. Direito Ambiental Contemporâneo. Barueri: Manole, 2004, p. 636-637.

${ }^{20}$ LEITE, J. R. M.; AYALA, P. A. Dano ambiental: do individual ao coletivo extrapatrimonial teoria e prática. 3. ed. São Paulo: RT, 2010. p. 23.

${ }^{21}$ SILVA, José Afonso. Direito AmbientalConstitucional. 6. ed. São Paulo: Malheiros, 2007.p. 86.

22 CANOTILHO, José Joaquim Gomes; LEITE, José Rubens Morato Leite. Direito ambiental constitucional brasileiro. São Paulo: Saraiva, 2010, p. 93.
} 
GRANADO, Juliete Ruana Madra; BONISSONI, Natammy Luana. O direito ambiental, o princípio da prevenção e o acesso à Avaliação Ambiental Estratégica. Revista Eletrônica Direito e Política, Programa de Pós-Graduação Stricto Sensu em Ciência Jurídica da UNIVALI, Itajaí, v.10, n.1, edição especial de 2015. Disponível em: www.univali.br/direitoepolitica - ISSN 1980-7791.

limpo. Considerou-se, portanto, o caráter dessa decisão como valorativo de assento constitucional"23.

Juarez Freitas ${ }^{24}$ destaca:

Traduz-se, portanto, a sustentabilidade, como dever fundamental de, a longo prazo, produzir e partilhar o desenvolvimento limpo e propício à saúde, em todos os sentidos, aí abrangidos os componentes primordialmente éticos, em combinação com os elementos sociais, ambientais, econômicos e jurídico-políticos.

Percebe-se então, diante da sociedade de risco $^{25}$, a predominância da proteção ao meio ambiente como uma condição necessária e indispensável à conservação da vida humana, tornando-se, portanto, indispensável a criação de Estados Constitucionais Ambientais.

Registre-se, ainda, e isto é fato, que o tratamento a ser oferecido com o intuito de proteger e manter o meio ambiente equilibrado para as futuras gerações é de caráter extremamente relevante, não devendo ser tratado somente dentro das fronteiras do Estado nacional, para tanto, deve ser elevado como assunto de interesse internacional, em escala global. ${ }^{26}$

\section{O ESTRATO PREVENTIVO: OS APORTES DO PRINCÍPIO DA PREVENÇÃO NA CONSECUÇÃO DA PROTEÇÃO AMBIENTAL}

Com o passar dos tempos e o com o avanço da modernidade tem se tornado imprescindível a necessidade da preservação ambiental ser debatida no cenário mundial com a finalidade de minimizar todos os anos de descuido e negligência para com meio ambiente.

\footnotetext{
${ }^{23}$ FREITAS, Juarez. Sustentabilidade: direito ao futuro. 2. ed. Belo Horizonte: Fórum, 2012, p. 120

${ }^{24}$ FREITAS, Juarez. Sustentabilidade: direito ao futuro. p. 40

${ }^{25}$ BECK, Ulrich. Sociedade de risco: rumo a uma outra modernidade. Tradução de Sebastião Nascimento. São Paulo: Ed. 34, 2010.

${ }^{26}$ BONISSONI, Natammy Luana de Aguiar; DANTAS, Marcelo Buzaglo; FERRER, Gabriel Real. O Processo deinternacionalização da proteção ambiental e dos direitos humanos. In:Direito e transnacionalização.CRUZ,Paulo Márcio; DANTAS, Marcelo BuzagloDanta.Itajaí : UNIVALII, 2013.
} 
GRANADO, Juliete Ruana Madra; BONISSONI, Natammy Luana. O direito ambiental, o princípio da prevenção e o acesso à Avaliação Ambiental Estratégica. Revista Eletrônica Direito e Política, Programa de Pós-Graduação Stricto Sensu em Ciência Jurídica da UNIVALI, Itajaí, v.10, n.1, edição especial de 2015. Disponível em: www.univali.br/direitoepolitica - ISSN 1980-7791.

Tratar a proteção ao meio ambiente por meio de uma ótica global tem sido um fator relevante merecedor de total atenção e dedicação, tendo em vista ter sido necessário que o meio ambiente apresentasse os primeiros sinais de desequilibro para que tal atenção especial fosse efetivamente consumada.

A humanidade com o passar do tempo e mediante diversos resultados científicos começou a possuir o conhecimento de inúmeros fatos referentes à crise ambiental, mas optou por ficar inerte e fingir desconhecer, a real face da crise ambiental. Deste modo, compreende-se como essencial o estudo acerca da garantia da proteção ambiental como tentativa de prevenir e adiar a extinção da raça humana, palavras citadas pelo Professor Gabriel Real Ferrer em sala de aula.

Para facilitar a compreensão acerca do processo de construção do Direito Ambiental, o Professor Gabriel propõe o estudo de três enfoques: Las olas, los estratos e La evolución conceptual.

Las olas, que significa "as ondas", compreendem os momentos políticos organizados pela comunidade internacional com o objetivo de alcançar a qualidade da questão ambiental. Para tanto, será considerado o progresso cronológico dos encontros realizados com tal finalidade. ${ }^{27}$

Como termo los estratos, "as fases", podem se considerar os avanços técnicos realizados na tentativa de resolver novas situações com impossibilidade de resolução fundamentada em instrumentos clássicos do direito. Logo, apresentam-se novas instituições jurídicas que com o passar do tempo são aprimoradas $^{28}$.

Por fim, compreende-se como La evolución conceptual, que se traduz em "a evolução conceitual", a abrangência de significados, objetivos e finalidades do estudo do Direito Ambiental. Considerada como o enfoque mais complexo, trata

\footnotetext{
${ }^{27}$ FERRER, Gabriel. La construccióndelderecho ambiental. Revista Novos Estudos Jurídicos NEJ. Vol. 18. n. 3. Disponível em: http://siaiweb06.univali.br/seer/index.php/nej.
}

${ }^{28}$ FERRER, Gabriel. La construcción Del derecho ambiental. Revista Novos Estudos Jurídicos NEJ. Vol. 18. n. 3. Disponível em: http://siaiweb06.univali.br/seer/index.php/nej. 
GRANADO, Juliete Ruana Madra; BONISSONI, Natammy Luana. O direito ambiental, o princípio da prevenção e o acesso à Avaliação Ambiental Estratégica. Revista Eletrônica Direito e Política, Programa de Pós-Graduação Stricto Sensu em Ciência Jurídica da UNIVALI, Itajaí, v.10, n.1, edição especial de 2015. Disponível em: www.univali.br/direitoepolitica - ISSN 1980-7791.

acerca da compreensão do direito ambiental como um todo "dónde estamos, para qué nos sirve, cuál e sel sustento". ${ }^{29}$

Tendo em vista las olas e la evolución conceptual tratarem respectivamente de uma construção histórica e conceitual, a presente pesquisa focará nos novos avanços relacionados à evolução técnica.

Esses avanços compreendidos em cinco fases de progresso ao movimento ambiental, quais sejam: a fase repressiva, que tem por objetivo a proteção do meio ambiente mediante a proibição e sanção de diversas condutas; a segunda fase, chamada fase preventiva, considerava a essencialidade da não existência ou diminuição do dano; a fase participativa é apresentada em seguida apontando a responsabilidade da proteção ambiental não somente ao governo, mas de toda a comunidade; a quarta é a que envolve a fase das técnicas de mercado e a internacionalização dos custos, a qual visa a dinâmica e a lógica interna do mercado para facilitar as decisões e ações favoráveis ao meio ambiente, como a economia verde; e por fim, a quinta envolve a fase das técnicas abrangentes, que consistem na utilização da mesma gestão ambiental em todo o processo, desde a obtenção de matérias-primas, através de processos de produção, de vida do produto e no alcance do seu destino final ${ }^{30}$.

Neste ponto, permite-se, mais uma vez, valer-se das palavras do Doutor Gabriel Real Ferrer ${ }^{31}$. Ao tratar sobre a fase preventiva o Professor destaca a relevância de se evitar os danos e a importância de enfatizar os aspectos preventivos que possam afetar diretamente o meio ambiente. Desta feita, surge uma nova instituição, a Avaliação de Impacto Ambiental. A saber:

Suoriginalidad consiste esencialmenteen que se constituye como unprocedimiento singular articulado exclusivamente para asegurarla toma em consideración de lãs consecuenciasambientales de determinados proyectos sometidos a decisión pública. [...] pero el decisivo avance

\footnotetext{
29 Pagina 2 - GABRIEL EL DERECHO AMBIENTAL Y EL DERECHO DE LA SOSTENIBILIDAD

${ }^{30}$ FERRER, Gabriel. La construccióndelderecho ambiental. Revista Novos Estudos Jurídicos NEJ. Vol. 18. n. 3, p. 353- 358. Disponível em: http://siaiweb06.univali.br/seer/index.php/nej.

31 FERRER, Gabriel. La construccióndelderecho ambiental. Revista Novos Estudos Jurídicos NEJ. Vol. 18. n. 3, p. 353- 356. Disponível em: http://siaiweb06.univali.br/seer/index.php/nej.
} 
GRANADO, Juliete Ruana Madra; BONISSONI, Natammy Luana. O direito ambiental, o princípio da prevenção e o acesso à Avaliação Ambiental Estratégica. Revista Eletrônica Direito e Política, Programa de Pós-Graduação Stricto Sensu em Ciência Jurídica da UNIVALI, Itajaí, v.10, n.1, edição especial de 2015. Disponível em: www.univali.br/direitoepolitica - ISSN 1980-7791.

que suponela EIA y su generalizado éxito, se debe a que es un procedimento concebido para tener em cuentaúnicamente La repercusión ambiental de um proyecto, lo que dará lugar a una declaración -positiva o negativareferida a esos solos efectos.

Cumpre salientar que mesmo a Avaliação Ambiental Estratégica não tenha sido citada expressamente como instrumento de efetivação do princípio da prevenção, nota-se que tal mecanismo também se adequa como ferramenta para a fase de prevenção.

Nota-se que diferente da Avaliação de Impacto Ambiental, criticada por Gabriel Real Ferrer como mecanismo limitado que atua somente sobre um projeto, destaca-se a AAE pelo fato de consistir em um processo mais abrangente, o qual, por consequência, apresentará uma maior efetividade e repercussão na consecução da proteção ambiental. ${ }^{32}$

Nesse contexto, a real necessidade de se adotar um instrumento de política ambiental com as finalidades da AAE é de real notoriedade, muito embora o seu desenvolvimento ainda possa despertar algumas discussões. Posto isso, compete analisar a Avaliação Ambiental Estratégica como um instrumento de acesso ao meio ambiente sadio e equilibrado, fato que ainda não é realidade na ordem jurídica nacional.

\section{A INSTRUMENTALIZAÇÃO EFICAZ DO PRINCÍPIO PREVENTIVO: UM RECURSO PARA A AVALIAÇÃO AMBIENTAL ESTRATÉGICA}

Pelo escorço, viu-se que a ideia de proteção ambiental engloba tanto as atividades de reparação, quanto as ações de prevenção. Nota-se que o paradigma trazido pela fase preventiva tem sido, logicamente, o ideal mais eficiente de preservação ambiental. Isto porque, sem sombra de dúvidas, antes

\footnotetext{
${ }^{32}$ SOUZA, Maria Claudiada Silva Antunesde; MAFRA, JulieteRuana.A sustentabilidade e seus reflexos dimensionais na Avaliação Ambiental Estratégica: o ciclo do equilíbrio do bem estar. In: LiviaGaigherBosio Campello; Norma Suelli Padilha, Paulo de Bessa Antunes. (Org.). DIREITO AMBIENTAL I: XXIII ENCONTRO NACIONAL DO CONPEDI. 1ed.Itajaí: Univali, 2014, v. 1, p. 23.
} 
GRANADO, Juliete Ruana Madra; BONISSONI, Natammy Luana. O direito ambiental, o princípio da prevenção e o acesso à Avaliação Ambiental Estratégica. Revista Eletrônica Direito e Política, Programa de Pós-Graduação Stricto Sensu em Ciência Jurídica da UNIVALI, Itajaí, v.10, n.1, edição especial de 2015. Disponível em: www.univali.br/direitoepolitica - ISSN 1980-7791.

de se remediar um gravame, melhor é sempre prevenir sua ocorrência.

Sobre o princípio da prevenção, Marcelo Abelha Rodrigues ${ }^{33}$ ensina que:

Sua importância está diretamente relacionada ao fato de que, se ocorrido o dano ambiental, a sua reconstituição é praticamente impossível. O mesmo ecossistema jamais pode ser revivido. Uma espécie extinta é um dano irreparável. Uma floresta desmatada causa uma lesão irreversível, pela impossibilidade de reconstituição da fauna e da flora e de todos os componentes ambientais em profundo e incessante processo de equilíbrio, como antes se apresentavam.

Assim, melhor que reparar as mazelas ambientais é repreender o cometimento dos danos, prevenir é sempre melhor que remediar.

Ocorre que a proteção ao meio ambiente sadio e equilibrado, em respaldo a sua conservação ecológica, consiste em direito fundamental que, para encontrar eficácia, precisa adotar um modelo de desenvolvimento econômico diferente, que inclua em seus projetos, a variante da preservação ambiental.

É preciso que se analisem os impactos que serão acarretados à natureza com a escolha de uma ou outra atividade. Com essa preocupação preventiva que se haverá a concretização do princípio do desenvolvimento sustentável ${ }^{34}$, para tanto, indaga-se: qual medida coativa hábil a instrumentalizar a prevenção ambiental eficientemente?

A Avaliação Ambiental Estratégica é instrumento que vem ganhando repercussão no cenário jurídico global, em favor de respaldar o Direito Ambiental ${ }^{35}$.

33 RODRIGUES, Marcelo Abelha. Elementos de direito ambiental: Parte Geral. 2. ed. São Paulo: Editora Revista dos Tribunais, 2005. p. 203.

34 SOARES, G. F. S. Direito internacional do meio ambiente: emergência, obrigações e responsabilidades. São Paulo: Atlas, 2001.p. 175-176.

35 O presente tópico deste artigo científico se compõe por pesquisa que também resulta das contribuições feitas em outra obra científica, o qual já fora publicada por parte destes autores, em que se contém semelhante aporte temático. SOUZA, Maria Claudia Silva Antunes de Souza; MAFRA, JulieteRuana. A sustentabilidade no alumiar de Gabriel Real Ferrer: reflexos dimensionais na Avaliação Ambiental Estratégica In: SOUZA, Maria Claudia Silva Antunes de Souza; GARCIA, Heloise Siqueira Org(s). Lineamentos sobre sustentabilidade segundo Gabriel Real Ferrer. Itajaí: UNIVALI, 2014.p. 11-37. Disponível em: http://siaiapp28.univali.br/LstFree.aspx. Acesso em: 28 de julho de 2014. 
GRANADO, Juliete Ruana Madra; BONISSONI, Natammy Luana. O direito ambiental, o princípio da prevenção e o acesso à Avaliação Ambiental Estratégica. Revista Eletrônica Direito e Política, Programa de Pós-Graduação Stricto Sensu em Ciência Jurídica da UNIVALI, Itajaí, v.10, n.1, edição especial de 2015. Disponível em: www.univali.br/direitoepolitica - ISSN 1980-7791.

No que concerne à terminologia da Avaliação Ambiental Estratégica, o Ministério do meio ambiente do Brasil ${ }^{36}$, por meio da Secretaria de Qualidade Ambiental nos Assentamentos Humanos (SQA), menciona que:

A expressão avaliação ambiental estratégica corresponde à tradução direta da inglesa strategicenvironmentalassessment, designação genérica que se convencionou adotar para identificar o processo de avaliação ambiental de políticas, planos e programas. Tanto em inglês como em português a expressão não reúne o consenso dos profissionais da área de meio ambiente. A razão é de ordem etimológica e deve-se aos conceitos de meio ambiente e estratégia, revelando-se na aplicação prática as interpretações distintas da AAE.Com efeito, a designação adotada tem influenciado a comunicação sobre a matéria, bem como sua percepção por parte dos que a promovem e utilizam. (...) Quaisquer que sejam os conceitos de meio ambiente e estratégia que se adotem, terá que existir sempre uma estratégia objeto de avaliação e, portando, de aplicação da $A A E$, e a avaliação ambiental deverá ser feita na mais ampla concepção de meio ambiente, considerando-se integralmente todas as suas dimensões e os princípios da sustentabilidade.

Já quanto à conceituação, vê-se que definir a Avaliação Ambiental Estratégica AAE não é tarefa fácil, poucos que se aventuram sobre o tema, chegam a entender que a AAE é a avaliação ambiental de políticas, planos e programas. E muitos conceituam o instituto como mera avaliação ambiental em qualquer nível acima ou anterior ao dos projetos arquitetônicos ou de implantação de atividades produtivas $^{37}$.

36 BRASIL. MMA - Ministério do Meio Ambiente. Secretaria de Qualidade Ambiental nos Assentamentos Humanos (SQA). Manual sobre a Avaliação Ambiental Estratégica. Brasília: MMA/SQA. 2002. p. 14.

37 PARTIDÁRIO, Maria do Rosário. Guia de boas práticas para Avaliação Ambiental Estratégica. Agência Portuguesa do Ambiente. Amadora: 2007. p. 11. Disponível em: http://www.ced.cl/ced/wp-content/uploads/2011/10/guia_aae_pt.pdf. Acesso 15 fevereiro de 2014. 
GRANADO, Juliete Ruana Madra; BONISSONI, Natammy Luana. O direito ambiental, o princípio da prevenção e o acesso à Avaliação Ambiental Estratégica. Revista Eletrônica Direito e Política, Programa de Pós-Graduação Stricto Sensu em Ciência Jurídica da UNIVALI, Itajaí, v.10, n.1, edição especial de 2015. Disponível em: www.univali.br/direitoepolitica - ISSN 1980-7791.

Sobre a temática, Riki Therivel ${ }^{38}$ diz que: "a avaliação ambiental estratégica $(A A E)$ é um processo que tem por objetivo integrar o meio ambiente e considerações sustentáveis no processo de tomada de decisões estratégicas".

Sadler e Verheem ${ }^{39}$ lecionam que a "AAE é um processo sistemático para avaliar as consequências ambientais de uma política, plano ou programa, de forma a assegurar que elas sejam integralmente incluídas e apropriadamente consideradas no estágio inicial e apropriado do processo de tomada de decisão, juntamente com as considerações de ordem econômicas e sociais".

Sobre o tema, Partidário ${ }^{40}$ conceitua a AAE conforme segue:

Avaliação Ambiental Estratégica é o procedimento
sistemático e contínuo de avaliação da qualidade do meio
ambiente e das conseqüências ambientais decorrentes de
visões e intenções alternativas de desenvolvimento,
incorporadas em iniciativas tais como a formulação de
políticas, planos e programas (PPP), de modo a assegurar a
integração efetiva dos aspectos biofísicos, econômicos,
sociais e políticos, o mais cedo possível, aos processos
públicos de planejamento e tomada de decisão.

Para Federico Rodrigues Silva ${ }^{41}$ :

Avaliação Ambiental Estratégica - AAE é o termo usado para descrever o processo de avaliação dos impactos ambientais de ações estratégicas que ocorrem em todos os níveis

38 THERIVEL, Riki. Strategic Enviromental in Action. 2. ed. Washignton DC: earthscan, 2010. p.3.

${ }^{39}$ SADLER, B.; VERHEEM, R. 1996.Status, Challenges and Future Directions.Strategic Environmental Assessmentapud EGLER, Paulo César Gonçalves. Perspectivas de uso no Brasil do processo de Avaliação Ambiental Estratégica. Disponível em http://seer.cgee.org.br/index.php/parcerias_estrategicas/article/view/166/160. Acesso em 13 . ago. 2013.

40 PARTIDÁRIO, Maria do Rosário. Guia de boas práticas para Avaliação Ambiental Estratégica. p 12-29.

${ }^{41}$ SILVA, Frederico Rodigues. AVALIAÇÃO AMBIENTAL ESTRATÉGICA COMO INSTRUMENTO DE PROMOÇÃO DO DESENVOLVIMENTO SUSTENTÁVEL.UniBrasil - Faculdades Integradas do Brasil. Revista Direitos Fundamentais \& democracia. Disponível em <revistaeletronicardfd.unibrasil.com.br>. ISSN 1982-0496. V. 8, n. 8, (jul./dez. 2010), p. 301329. 
GRANADO, Juliete Ruana Madra; BONISSONI, Natammy Luana. O direito ambiental, o princípio da prevenção e o acesso à Avaliação Ambiental Estratégica. Revista Eletrônica Direito e Política, Programa de Pós-Graduação Stricto Sensu em Ciência Jurídica da UNIVALI, Itajaí, v.10, n.1, edição especial de 2015. Disponível em: www.univali.br/direitoepolitica - ISSN 1980-7791.

decisórios governamentais que precedem a fase de projetos específicos. Ou seja, é uma forma de análise e avaliação de impacto de ações e consequências ambientais nos níveis mais estratégicos de decisão das Políticas, Planos e Programas - PPP's - de intervenção estatal, sejam setoriais, regionais, ou em áreas programáticas. A AAE seria, então, um instrumento de política ambiental sistemático, público, participativo e democrático, que objetiva promover o desenvolvimento sustentável através da incorporação da variável ambiental no processo de planejamento estratégico das políticas públicas.

Sadler e Verheem ${ }^{42}$ indicam que "os blocos de construção da abordagem estratégica para a avaliação ambiental derivam das experiências com a AIA de projetos", logo, experiências passadas e as lições adquiridas em aplicações de políticas e de planejamento de instrumentos baseados em AIA, orientam os estudos contemporâneos sobre a AAE.

Entretanto, o conceito de Avaliação Ambiental Estratégica não deve se confundir com a ideia de Avaliação de Impactos Ambientais - AIA, isso é o que orienta o Ministério do Meio Ambiente do Brasil. Veja-se.

A AAE é um instrumento de caráter político e técnico e tem a ver com conceitos e não com atividades específicas em termos de concepções geográficas e tecnológicas. Pode-se concluir, portanto, que a $\mathrm{AAE}$ não se confunde com:a avaliação de impacto ambiental de grandes projetos, como os de rodovias, aeroportos ou barragens, que normalmente afetam uma dada área ou um local específico, envolvendo apenas um tipo de atividade; as políticas, planos ou programas de desenvolvimento integrado que, embora incorporem algumas questões ambientais em suas formulações, não tenham sido submetidos aos estágios operacionais de avaliação ambiental, em especial, à uma

\footnotetext{
${ }^{42}$ Sadler, B. and R. Verheem. 1996. Status, Challenges and Future Directions. Strategic Environmental Assessmentapud EGLER, Paulo César Gonçalves. Perspectivas de uso no Brasil do processo de Avaliação Ambiental Estratégica. Disponível em http://seer.cgee.org.br/index.php/parcerias_estrategicas/article/view/166/160. Acesso em 13. ago. 2013.
} 
GRANADO, Juliete Ruana Madra; BONISSONI, Natammy Luana. O direito ambiental, o princípio da prevenção e o acesso à Avaliação Ambiental Estratégica. Revista Eletrônica Direito e Política, Programa de Pós-Graduação Stricto Sensu em Ciência Jurídica da UNIVALI, Itajaí, v.10, n.1, edição especial de 2015. Disponível em: www.univali.br/direitoepolitica - ISSN 1980-7791.

apreciação de alternativas baseada em critérios e objetivos ambientais, com vista à tomada de decisão; eos relatórios de qualidade ambiental ou as auditorias ambientais, cujos objetivos incluem o controle periódico ou a gestão de impactos ambientais das atividades humanas, mas que não possuem como objetivo específico informar previamente a decisão relativa aos prováveis impactos de alternativas de desenvolvimento.

Neste diapasão, Souza ${ }^{43}$ diz que a Avaliação Ambiental Estratégica "é a face da 'avaliação de impacto ambiental' que pode, no caso da realidade institucional brasileira, exercer importante papel no processo de desenvolvimento na maneira de se fazer avaliação de impacto ambiental" e, complementa que: "sobretudo, no uso da avaliação de impacto ambiental como instrumento de direcionamento do planejamento urbano".

Ademais, Egler ${ }^{44}$ orienta que existem três tipos principais de ação que comportam serem submetidas ao processo da Avaliação Ambiental Estratégica, as quais são:

1) $\mathrm{PPP}^{45} \mathrm{~s}$ setoriais (e.g. energia e transporte); 2) PPPs relacionados com o uso do território, o qual cobre todas as atividades a serem implementadas em uma determinada área e; 3) políticas ou ações que não necessariamente se implementam por meio de projetos, mas que podem ter impactos ambientais significativos (e.g. política de incentivos ou de créditos). O principal problema com essa tripla contextualização da aplicação do processo de AAE é a natureza integrada desses três tipos de ações apontadas, uma vez que é impossível discutir uma política, plano ou programa setorial sem ligá-los ao território onde serão

\footnotetext{
43 SOUZA, Cristiane Mansur de Moraes.Avaliação Ambiental Estratégica (AAE): Limitações Dos Estudos De Impacto Ambiental (EIA). XVII Simpósio Brasileiro de Recursos Hídricos. Disponível em http://www.abrh.org.br/SGCv3/UserFiles/Sumarios/aecc27600b3c1d428ebb592f40d89e36_27610e ae631ce836849ff563173b0a70.pdf. Acesso em 13 ago. 2013. p. 3.

44 GONÇALVES, Paulo César. Perspectivas de uso no Brasil do processo de Avaliação Ambiental Estratégica. http://seer.cgee.org.br/index.php/parcerias_estrategicas/article/view/166/160. Acesso em 13 . ago. 2013. p. 3.

${ }^{45} \mathrm{PPP}^{\prime} \mathrm{s}$ - Política, planos e programas.
} 
GRANADO, Juliete Ruana Madra; BONISSONI, Natammy Luana. O direito ambiental, o princípio da prevenção e o acesso à Avaliação Ambiental Estratégica. Revista Eletrônica Direito e Política, Programa de Pós-Graduação Stricto Sensu em Ciência Jurídica da UNIVALI, Itajaí, v.10, n.1, edição especial de 2015. Disponível em: www.univali.br/direitoepolitica - ISSN 1980-7791.

implantados, e também ao contexto político e ideológico onde a política, o plano e o programa foram concebidos e aprovados.

Desta maneira, é compreensível que a designação da AAE no Brasil e na União Europeia seja a mesma exprimida em todo o seio global, vista como um processo sistemático para avaliar as consequências ambientais das políticas estatais, isto com o escopo de viabilizar a consecução do tão desejado desenvolvimento sustentável.

Muitos são os objetivos e a conveniência de se conceder aplicabilidade ao fenômeno da Avaliação Ambiental Estratégica, porquanto consiste em instrumento que viabiliza a efetiva prevenção de danos ambientais futuros e a diminuição dos impactos ambientais presentes ${ }^{46}$.

É tratando da conveniência da AAE no Brasil que Egler" assevera o que: "três aspectos podem ser apontados para reforçar a oportunidade e a relevância do processo de AAE para o Brasil". No que tange ao primeiro aspecto:

O primeiro é a natureza significativamente diferente das intervenções feitas no território brasileiro, quando comparadas com aquelas feitas em países como os europeus ou os Estados Unidos. Diferentemente desses países, o Brasil ainda dispõe de imensas áreas a serem ocupadas e o atual projeto dos Eixos de Desenvolvimento, lançado pelo Programa Avança Brasil, é um exemplo expressivo dessa realidade. Assim, o uso de um procedimento de avaliação como o processo de $A A E$, o qual é concebido para analisar os impactos ambientais e sociais de políticas, planos e programas de desenvolvimento, é muito mais apropriado para a situação brasileira do que o processo de AIA, que tem aplicação restrita a projetos. É de certa forma evidente que se, por exemplo, as intervenções do Setor Elétrico na Amazônia tivessem sido analisados e avaliados por um processo mais amplo, ao invés da elaboração de AIAs para cada empreendimento, os resultados relativamente à

46 BRASIL. MMA- Ministério do Meio Ambiente. Secretaria de Qualidade Ambiental nos Assentamentos Humanos (SQA). Manual sobre a Avaliação Ambiental Estratégica. p. 14.

47 EGLER, Paulo César Gonçalves. Perspectivas de uso no Brasil do processo de Avaliação Ambiental Estratégica. 
GRANADO, Juliete Ruana Madra; BONISSONI, Natammy Luana. O direito ambiental, o princípio da prevenção e o acesso à Avaliação Ambiental Estratégica. Revista Eletrônica Direito e Política, Programa de Pós-Graduação Stricto Sensu em Ciência Jurídica da UNIVALI, Itajaí, v.10, n.1, edição especial de 2015. Disponível em: www.univali.br/direitoepolitica - ISSN 1980-7791.

qualidade dos contextos sociais e ambientais naquela Região teriam sido significativamente diferentes ${ }^{48}$.

No que tange ao segundo aspecto que reforça a aplicação da AAE no Brasil, consiste nos esforços que já foram feitos, seja em nível federal como estadual, para por em prática o Programa de Zoneamento Ecológico Econômico - ZEE ${ }^{49}$. Sobre ele, Egler ainda diz que:

Como um dos principais objetivos do ZEE é o desenvolvimento de um processo de avaliação do uso do território que venha a considerar, de forma efetiva, no processo de tomada de decisão a integração dos domínios econômico, social e ambiental, é possível se afirmar que o ZEE e a AAE partilham objetivos comuns. Dessa forma, a implantação da AAE no País pode vir a representar um reforço para o ZEE e vice versa. Nesse sentido, o ZEE como proposta de desenvolvimento vem de encontro aos interesses da sustentabilidade que tanto clamam pela definição de políticas mais adequadas para o desenvolvimento regional e local, tendo também a sociedade como partícipe, fato que é intrínseco em sua metodologia básica e igualmente na da AAE. Cabe também apontar que o ZEE contém os subsídios técnicos para a regulação e a promoção dos melhores usos dos espaços geográficos, mediante a orientação e a indicação de ações preventivas e corretivas, através das políticas territoriais, legislações específicas e instrumentos de caráter jurídicoadministrativo ${ }^{50}$.

Por fim, mas não menos importante, o terceiro aspecto é a evidência de que acerca da arena ambiental a aplicação do ditado 'o pequeno é bonito' (small is beautiful), nem sempre se aplica. Para se colocar essa questão de uma forma mais clara, impõe-se indicar que os diferentes documentos e estudos sobre a

48 EGLER, Paulo César Gonçalves. Perspectivas de uso no Brasil do processo de Avaliação Ambiental Estratégica. Disponível http://seer.cgee.org.br/index.php/parcerias_estrategicas/article/view/166/160. Acesso em 13 . ago. 2013. p. 12-14.

49 EGLER, Paulo César Gonçalves. Perspectivas de uso no Brasil do processo de Avaliação Ambiental Estratégica. Disponível em http://seer.cgee.org.br/index.php/parcerias_estrategicas/article/view/166/160. Acesso em 13 . ago. 2013. p. 12-14.

${ }^{50}$ EGLER, Paulo César Gonçalves. Perspectivas de uso no Brasil do processo de Avaliação Ambiental Estratégica. Disponível ago. 2013. p. 12-14. 
GRANADO, Juliete Ruana Madra; BONISSONI, Natammy Luana. O direito ambiental, o princípio da prevenção e o acesso à Avaliação Ambiental Estratégica. Revista Eletrônica Direito e Política, Programa de Pós-Graduação Stricto Sensu em Ciência Jurídica da UNIVALI, Itajaí, v.10, n.1, edição especial de 2015. Disponível em: www.univali.br/direitoepolitica - ISSN 1980-7791.

AAE elaborados em nível internacional têm apontado que a prática do planejamento é fundamental para a questão ambiental e, mais especificamente, para a viabilização do Desenvolvimento Sustentável. O que é clarividente através das demandas impostas pelo processo de AAE é a necessidade de que o ambiente seja pensado a partir de uma perspectiva mais ampla - global, regional, local e setorial ${ }^{51}$.

É por isso que a AAE consiste em processo que contribuiu, diretamente, para a prevenção do meio ambiente e para o Desenvolvimento Sustentável, pois age a fim de gerar um contexto de decisão mais amplo e integrado com a proteção ambiental e a melhor capacidade de avaliação de impactos cumulativos, exigindo um estudo estratégico antes da tomada de decisão, ou seja, prescindindo a ocorrência do dano ambiental, visando evitá-lo ou, ao menos, mitigá-lo.

É cediço que a legislação ambiental brasileira encontra fundamento vigente na Constituição da República Federativa do Brasil de 1988 e na Lei n 6.938/1981, que regula a Política Nacional do Meio Ambiente, mas não há qualquer norma específica institucionalizada sobre o tema em âmbito nacional, isto para a regulamentação de seu processo regulatório.

Em 1994, houve em São Paulo a tentativa de se institucionalizar a $A A E$, em decorrência do reconhecimento das limitações do processo de AIA e em função da necessidade de se avaliar as consequências ambientais das políticas e programas setoriais. O Conselho Estadual de Meio Ambiente - CONSEMA editou a Resolução SMA-44, que criava a Comissão de Avaliação Ambiental Estratégica, subordinada ao Secretário Estadual de Meio Ambiente, com a atribuição de analisar a introdução da variável ambiental em PPP governamental de interesse público ${ }^{52}$.

${ }^{51}$ EGLER, Paulo César Gonçalves. Perspectivas de uso no Brasil do processo de Avaliação Ambiental Estratégica. Disponível em http://seer.cgee.org.br/index.php/parcerias_estrategicas/article/view/166/160. Acesso em 13 . ago. 2013. p. 12-14.

52 O histórico que se inicia neste ponto encontra-se descrito no Manual de Avaliação Ambiental Estratégica desenvolvido pelo Ministério do Meio Ambiente. MMA. Avaliação Ambiental Estratégica. Brasília: MMA/SQA. 2002. p. 44 e ss. 
GRANADO, Juliete Ruana Madra; BONISSONI, Natammy Luana. O direito ambiental, o princípio da prevenção e o acesso à Avaliação Ambiental Estratégica. Revista Eletrônica Direito e Política, Programa de Pós-Graduação Stricto Sensu em Ciência Jurídica da UNIVALI, Itajaí, v.10, n.1, edição especial de 2015. Disponível em: www.univali.br/direitoepolitica - ISSN 1980-7791.

De acordo com a resolução, ao CONSEMA e à Secretaria Estadual de Meio Ambiente - SMA cabiam as seguintes atribuições: avaliar as consequências ambientais das diretrizes setoriais; definir o conteúdo e elaborar termos de referência para a elaboração dos estudos; analisar os seus resultados; e produzir relatórios e pareceres sobre a aprovação das AAE dos PPP's.

Como desdobramento da edição da Resolução SMA-44/94, a SMA encomendou, em 1997, a realização de um estudo denominado Procedimentos Alternativos para a Operacionalização da AAE no Sistema Estadual de Meio Ambiente, que envolveu: o levantamento do estado da arte da experiência internacional; a proposição de diretrizes capazes de orientar o desenvolvimento da AAE no Estado de São Paulo, com base na análise da base institucional vigente e a formulação de procedimentos alternativos para a regulamentação da matéria.

Segundo Ministério do Meio Ambiente, o estudo criticou o fato de a Resolução SMA-44/94 induzir a reprodução do modelo de AIA - em que a análise e aprovação dos EIAs era realizada pelo CONSEMA -, com o risco de se instituir um processo de licenciamento ambiental de PPPs ao invés de um novo processo de $A A E^{53}$.

Apesar da realidade atual da Avaliação Ambiental Estratégica se mostrar muito mais tímida no Brasil do que na maioria dos países europeus, sua adoção vem sendo incentivada pelo Ministério do Meio Ambiente desde 2002, a partir da elaboração do Manual de Avaliação Ambiental Estratégica.

A regulamentação da AAE seria importante para legitimar os seus, condutores em virtude da necessária articulação institucional e promoção de ações vitais para a participação popular no processo, além de viabilizar a alocação de recursos humanos e financeiros para sua implementação.

A necessidade de regulamentação legal da aplicação da $A A E$ também é reconhecida pelo próprio Ministério do Meio Ambiente, o qual no Manual

53 O histórico discorrido que se finda neste ponto encontra-se descrito no Manual de Avaliação Ambiental Estratégica desenvolvido pelo Ministério do Meio Ambiente. MMA. Avaliação Ambiental Estratégica. Brasília: MMA/SQA. 2002. p. 44 e ss. 
GRANADO, Juliete Ruana Madra; BONISSONI, Natammy Luana. O direito ambiental, o princípio da prevenção e o acesso à Avaliação Ambiental Estratégica. Revista Eletrônica Direito e Política, Programa de Pós-Graduação Stricto Sensu em Ciência Jurídica da UNIVALI, Itajaí, v.10, n.1, edição especial de 2015. Disponível em: www.univali.br/direitoepolitica - ISSN 1980-7791.

divulgado, destaca que para a instituição da AAE no País, é todo necessário criar uma base legal mínima que apoie e facilite sua implementação e que, pelo menos, determine as responsabilidades dos órgãos e das instituições encarregadas da formulação de política e do planejamento; as instâncias e fontes de recurso para a realização dos estudos; as instâncias encarregadas da revisão do processo; o papel dos órgãos e instituições de meio ambiente; e os mecanismos de consulta aos grupos de interesse $e^{54}$.

Vale destacar que, no Brasil, já tramitou na Câmara dos Deputados o Projeto de Lei no 2.072/03, elaborado pelo deputado Fernando Gabeira ${ }^{55}$, que pretendia a institucionalização da AAE no âmbito federal. Por meio de alteração da Lei no 6.938, de 31 de agosto de 1981, o projeto previa a realização da AAE no processo de formulação de PPPs, definindo as regras básicas desse instrumento. De acordo com a proposta, os órgãos da administração pública direta e indireta responsáveis pela formulação de PPPs ficariam obrigados a realizar a AAE dos PPPs que formulassem. Ocorre que o projeto de lei foi arquivado na Mesa Diretora da Câmara dos Deputados ${ }^{56}$.

Em 21 de março de 2011, o Deputado Marçal Filho apresentou o Projeto de Lei n. 261/2011, que visa, novamente, alterar a Lei no 6.938 , de 31 de agosto de 1981, a fim de dispor sobre a Avaliação Ambiental Estratégica de políticas, planos e programas, na mesma perspectiva do projeto de Gabeira. Em análise, a Comissão de Trabalho, de Administração e Serviço Público (CTASP) foi contrária por entender, em suma, que aumentaria os gastos públicos, já a Comissão de Meio Ambiente e Desenvolvimento Sustentável (CMADS) foi favorável ao projeto, restando a análise da Comissão de Constituição e Justiça e de Cidadania

\footnotetext{
${ }^{54}$ MMA. Avaliação Ambiental Estratégica. Brasília: MMA/SQA. 2002. p.68.

${ }^{55}$ GABEIRA, Fernando. Projeto de Lei n. 2.072/03. Altera a Lei n. ${ }^{\circ} 6.938$, de 31 de agosto de 1981 , a fim de dispor sobre a avaliação ambiental estratégica de políticas, planos e programas. Câmara dos Deputados, Brasília, 2003. Disponível em: http://www.camara.gov.br/sileg/integras/166730.pdf. Acesso em 20 de nov. 2013.

56 FILHO, Marçal. Projeto de Lei n. 261/2011. Disponível em: http://www.camara.gov.br/proposicoesWeb/fichadetramitacao?idProposicao=491399. Acesso em: 18 fevereiro de 2014.
} 
GRANADO, Juliete Ruana Madra; BONISSONI, Natammy Luana. O direito ambiental, o princípio da prevenção e o acesso à Avaliação Ambiental Estratégica. Revista Eletrônica Direito e Política, Programa de Pós-Graduação Stricto Sensu em Ciência Jurídica da UNIVALI, Itajaí, v.10, n.1, edição especial de 2015. Disponível em: www.univali.br/direitoepolitica - ISSN 1980-7791.

$(\mathrm{CCJC})^{57}$.

No dia 20 de fevereiro de 2013, houve apresentação do Projeto de Lei n. 4996/2013, pelo Deputado Sarney Filho, que também visa alterar a Lei n 6.938, de 31 de agosto de1981, tornando a Avaliação Ambiental Estratégica um dos instrumentos da Política Nacional de Meio Ambiente. O projeto foi apenso ao projeto de lei n. 261/2011, por consistir na mesma matéria.

A aplicação da AAE também tenta ganhar força pelos esforços realizados a fim de implementar o Programa de Zoneamento Ecológico Econômico - ZEE. Isto por que um dos principais objetivos do ZEE é o desenvolvimento de um processo de avaliação do uso do território que considere a integração dos domínios econômico, social e ambiental no processo de tomada de decisão. Assim, percebe-se que a AAE pode se apoiar nos subsídios técnicos do ZEE para facilitar o processo de definição de políticas adequadas para o desenvolvimento ${ }^{58}$.

Neste diapasão, a Avaliação Ambiental Estratégica se afigura como uma das ferramentas ambientais passíveis de avaliar os impactos ambientais antes mesmo da política, programa ou plano que o causará. É a tomada de decisão estratégica, viabilizando um estudo acurado e específico sobre o possível dano ambiental que porventura seria decorrente, o que permite sua total minoração ou até mesmo, a inocorrência deste.

Já não é mais tempo de se atuar depois do estrago, tentando remediar os problemas provenientes dos danos ambientais já causados. Há que se agir preventivamente, evitando a ocorrência de mais danos ambientais, a fim de viabilizar menos prejuízos ambientais para o seio social.

A Avaliação Ambiental Estratégica servirá para participar desde as formulações,

57 FILHO, Sarney. Projeto de Lei n. 4996/2013. Disponível em: http://www.camara.gov.br/proposicoesWeb/fichadetramitacao?idProposicao=565264. Acesso em: 18 fevereiro de 2014.

58 SILVA, Frederico Rodrigues. AVALIAÇÃO AMBIENTAL ESTRATÉGICA COMO INSTRUMENTO DE PROMOÇÃO DO DESENVOLVIMENTO SUSTENTÁVEL.UniBrasil - Faculdades Integradas do Brasil. Revista Direitos Fundamentais \& democracia. Disponível em <revistaeletronicardfd.unibrasil.com.br>. ISSN 1982-0496. V. 8, n. 8, (jul./dez. 2010). p. 321325. 
GRANADO, Juliete Ruana Madra; BONISSONI, Natammy Luana. O direito ambiental, o princípio da prevenção e o acesso à Avaliação Ambiental Estratégica. Revista Eletrônica Direito e Política, Programa de Pós-Graduação Stricto Sensu em Ciência Jurídica da UNIVALI, Itajaí, v.10, n.1, edição especial de 2015. Disponível em: www.univali.br/direitoepolitica - ISSN 1980-7791.

até o processo de desenvolvimento estratégico de políticas, planos e programas, atuando como sério instrumento garantidor da prevenção ambiental.

A AAE facilita a tomada de atitudes diferenciadas quanto ao futuro, contribuindo para processos mais eficientes de governança e orientando sobre as opções para o novo ordenamento das atuais bases de avaliação ambiental e decisão.

\section{CONSIDERAÇÕES FINAIS}

Durante o desenvolvimento do artigo foi possível compreender que a tutela ao meio ambiente recebeu tardiamente a atenção que the era merecida. Anos de descaso, após a descoberta da crise ambiental, tentaram ser remediados com as assinaturas de alguns documentos internacionais de compromisso à efetivação da proteção ambiental ou até mesmo com a tomada de decisões urgentes acerca de aspectos específicos.

$\mathrm{Na}$ presente pesquisa, o acesso ao meio ambiente equilibrado foi apresentado como um direito humano fundamental, configurado como direito de todos, bem de uso comum do povo e indispensável à qualidade de vida saudável. Esta caracterização ocorreu atentando ao tratamento oferecido com o objetivo de se proteger e estabelecer a manutenção do meio ambiente equilibrado para as futuras gerações.

Para facilitar a compreensão acerca do processo de construção do Direito Ambiental, o Professor Gabriel Real Ferrer propôs o estudo de três enfoques: Las olas, los estratos e La evolución conceptual.

A partir destas conceituações, compreendeu-se de carater essencial o estudo da garantia da proteção ambiental na tentativa de prevenir e adiar a extinção da vida humana, sendo o progresso ao movimento ambiental compreendido em cinco fases: fase repressiva, fase preventiva, fase participativa, fase das técnicas de mercado e internacionalização dos custos e, por fim, a fase das técnicas abrangentes. 
GRANADO, Juliete Ruana Madra; BONISSONI, Natammy Luana. O direito ambiental, o princípio da prevenção e o acesso à Avaliação Ambiental Estratégica. Revista Eletrônica Direito e Política, Programa de Pós-Graduação Stricto Sensu em Ciência Jurídica da UNIVALI, Itajaí, v.10, n.1, edição especial de 2015. Disponível em: www.univali.br/direitoepolitica - ISSN 1980-7791.

Ao enfatizar a fase preventiva, fase objeto de estudo do presente artigo, destacou-se a relevância de se evitar os danos e a importância de enfatizar os aspectos preventivos que possam afetar diretamente o meio ambiente. Igualmente, pôde-se constatar que o paradigma trazido pela fase preventiva tem sido o mais eficiente em questão de preservação ambiental.

Deste modo, foi apresentada a Avaliação Ambiental Estratégica como um mecanismo capaz de trazer efetividade para a prevenção ambiental, uma vez que corresponde num processo abrangente, o qual, por consequência, apresentará maior efetividade e repercussão na consecução da proteção ambiental.

Com efeito, sustenta-se que o instituto da Avaliação Ambiental Estratégica - AAE é caracterizado como um forte instrumento que possibilita a consecução da efetividade do princípio da prevenção na proteção ao meio ambiente. Por tais razões, a Avaliação Ambiental Estratégica pode ser um dos caminhos precursores da consecução ao desenvolvimento sustentável.

\section{REFERÊNCIAS DAS FONTES CITADAS}

ANTUNES, Paulo Bessa. Direito Ambiental. 8. ed. Rio de Janeiro: Lumen Juris, 2005.

BECK, Ulrich. Sociedade de risco: rumo a uma outra modernidade. Tradução de Sebastião Nascimento. São Paulo: Ed. 34, 2010.

BONISSONI, Natammy Luana de Aguiar; DANTAS, Marcelo Buzaglo; FERRER, Gabriel Real. O Processo de internacionalização da proteção ambiental e dos direitos humanos. In: Direito e transnacionalização. CRUZ, Paulo Márcio; DANTAS, Marcelo BuzagloDanta. Itajaí : UNIVALI, 2013.

BRASIL. MMA - Ministério do Meio Ambiente. Secretaria de Qualidade Ambiental nos Assentamentos Humanos (SQA). Manual sobre a Avaliação Ambiental Estratégica. Brasília: MMA/SQA. 2002. 
GRANADO, Juliete Ruana Madra; BONISSONI, Natammy Luana. O direito ambiental, o princípio da prevenção e o acesso à Avaliação Ambiental Estratégica. Revista Eletrônica Direito e Política, Programa de Pós-Graduação Stricto Sensu em Ciência Jurídica da UNIVALI, Itajaí, v.10, n.1, edição especial de 2015. Disponível em: www.univali.br/direitoepolitica - ISSN 1980-7791.

CANOTILHO, José Joaquim Gomes; LEITE, José Rubens Morato Leite. Direito ambiental constitucional brasileiro. São Paulo: Saraiva, 2010.

CAPRA, Fritjof. A Teia da vida. São Paulo: CULTRIX, 1996.

DIAS, Reinaldo. Gestão Ambiental - Responsabilidade Social e Sustentabilidade. São Paulo: Atlas, 2007.

EGLER, Paulo César Gonçalves. Perspectivas de uso no Brasil do processo de Avaliação Ambiental Estratégica. Disponível em http://seer.cgee.org.br/index.php/parcerias_estrategicas/article/view/166/160. Acesso em 13. ago. 2013.

FERRER, Gabriel. La construcción Del derecho ambiental. Revista Novos Estudos Jurídicos - NEJ. Vol. 18. n. 3. Disponível em: http://siaiweb06.univali.br/seer/index.php/nej.

FILHO, Marçal. Projeto de Lei n. 261/2011. Disponível em: http://www.camara.gov.br/proposicoesWeb/fichadetramitacao?idProposicao=491 399. Acesso em: 18 fevereiro de 2014.

FILHO, Sarney. Projeto de Lei n. 4996/2013. Disponível em: http://www.camara.gov.br/proposicoesWeb/fichadetramitacao?idProposicao $=565$ 264. Acesso em: 18 fevereiro de 2014.

FREITAS, Juarez. Sustentabilidade: direito ao futuro. 2. ed. Belo Horizonte: Fórum, 2012.

GABEIRA, Fernando. Projeto de Lei n.2.072/03. Altera a Lei n. ${ }^{0}$ 6.938, de 31 de agosto de 1981, a fim de dispor sobre a avaliação ambiental estratégica de políticas, planos e programas. Câmara dos Deputados, Brasília, 2003. Disponível em: http://www.camara.gov.br/sileg/integras/166730.pdf. Acesso em 20 de nov. 2013.

GONÇALVES, Paulo César. Perspectivas de uso no Brasil do processo de Avaliação Ambiental Estratégica. Disponível em 
GRANADO, Juliete Ruana Madra; BONISSONI, Natammy Luana. O direito ambiental, o princípio da prevenção e o acesso à Avaliação Ambiental Estratégica. Revista Eletrônica Direito e Política, Programa de Pós-Graduação Stricto Sensu em Ciência Jurídica da UNIVALI, Itajaí, v.10, n.1, edição especial de 2015. Disponível em: www.univali.br/direitoepolitica - ISSN 1980-7791.

http://seer.cgee.org.br/index.php/parcerias_estrategicas/article/view/166/160. Acesso em 13. ago. 2013.

LEITE, José Rubens Morato; FILHO, Ney de Barros Mello. Direito Ambiental Contemporâneo. Barueri: Manole, 2004.

LEITE, J. R. M.; AYALA, P. A. Dano ambiental: do individual ao coletivo extrapatrimonial - teoria e prática. 3. ed. São Paulo: RT, 2010.

MAFRA, JulieteRuana; COELHO, Luciana de Carvalho. Noções Gerais sobre o princípio da informação frente ao acesso à Avaliação Ambiental Estratégica. In: Denise Schmitt Siqueira Garcia. (Org.). GOVERNANÇA TRANSNACIONAL E SUSTENTABILIDADE. 1ed.Itajaí: Univali, 2014, v. 2, p. 128148.

PASOLD, Cesar Luis. Metodologia da pesquisa jurídica: Teoria e prática. 11 ed. Florianópolis: Conceito editorial/Milleniuum, 2008.

PARTIDÁRIO, Maria do Rosário. Guia de boas práticas para Avaliação Ambiental Estratégica. Agência Portuguesa do Ambiente. Amadora: 2007. p. 11. Disponível em: http://www.ced.cl/ced/wpcontent/uploads/2011/10/guia_aae_pt.pdf. Acesso 15 fevereiro de 2014.

POLÍTICA NACIONAL DO MEIO AMBIENTE. Disponível em http://www.planalto.gov.br/ccivil_03/leis/I6938.htm. Acesso em 27/11/13.

RODRIGUES, Marcelo Abelha. Elementos de direito ambiental:Parte Geral. 2. ed. São Paulo: Editora Revista dos Tribunais, 2005.

SADLER, B.; VERHEEM, R. 1996.Status, Challenges and Future Directions.Strategic Environmental Assessmentapud EGLER, Paulo César Gonçalves. Perspectivas de uso no Brasil do processo de Avaliação Ambiental Estratégica. Disponível em http://seer.cgee.org.br/index.php/parcerias_estrategicas/article/view/166/160. Acesso em 13. ago. 2013. 
GRANADO, Juliete Ruana Madra; BONISSONI, Natammy Luana. O direito ambiental, o princípio da prevenção e o acesso à Avaliação Ambiental Estratégica. Revista Eletrônica Direito e Política, Programa de Pós-Graduação Stricto Sensu em Ciência Jurídica da UNIVALI, Itajaí, v.10, n.1, edição especial de 2015. Disponível em: www.univali.br/direitoepolitica - ISSN 1980-7791.

SARLET, Ingo; FENSTERSEIFER, Tiago. Direito constitucional ambiental. 3. ed. São Paulo: Revista dos Tribunais, 2013.

SILVA, Geraldo Eulálio do Nascimento e. Direito ambiental internacional. Rio de Janeiro: Thex Ed. 2002.

SILVA, José Afonso. Direito AmbientalConstitucional. 6. ed. São Paulo: Malheiros, 2007.p. 86.

SILVA, Frederico Rodigues. AVALIAÇÃO AMBIENTAL ESTRATÉGICA COMO INSTRUMENTO DE PROMOÇÃO DO DESENVOLVIMENTO SUSTENTÁVEL.UniBrasil Faculdades Integradas do Brasil. Revista Direitos Fundamentais \& democracia. Disponível em <revistaeletronicardfd.unibrasil.com.br>. ISSN 1982-0496. V. 8, n. 8, (jul./dez. 2010), p. 301-329.

SOARES, G. F. S. Direito internacional do meio ambiente: emergência, obrigações e responsabilidades. São Paulo: Atlas, 2001.

SOUZA, Cristiane Mansur de Moraes.Avaliação Ambiental Estratégica (AAE): Limitações Dos Estudos De Impacto Ambiental (EIA). XVII Simpósio Brasileiro de Recursos Hídricos.

Disponível

em http://www.abrh.org.br/SGCv3/UserFiles/Sumarios/aecc27600b3c1d428ebb592f 40d89e36_27610eae631ce836849ff563173b0a70.pdf. Acesso em 13 ago. 2013.

SOUZA, Maria Claudia Silva Antunes de Souza; MAFRA, JulieteRuana. A sustentabilidade no alumiar de Gabriel Real Ferrer: reflexos dimensionais na Avaliação Ambiental Estratégica. In: SOUZA, Maria Claudia Silva Antunes de Souza; GARCIA, Heloise Siqueira Org(s). Lineamentos sobre sustentabilidade segundo Gabriel Real Ferrer.Itajaí: UNIVALI, 2014.p. 1137. Disponível em: http://siaiapp28.univali.br/LstFree.aspx. Acesso em: 28 de julho de 2014.

SOUZA, Maria Claudia da Silva Antunes de; MAFRA, JulieteRuana. A sustentabilidade e seus reflexos dimensionais na Avaliação Ambiental Estratégica: o ciclo do equilíbrio do bem estar. In: LiviaGaigherBosio Campello; Norma Suelli Padilha, Paulo de Bessa Antunes. (Org.). DIREITO 
GRANADO, Juliete Ruana Madra; BONISSONI, Natammy Luana. O direito ambiental, o princípio da prevenção e o acesso à Avaliação Ambiental Estratégica. Revista Eletrônica Direito e Política, Programa de Pós-Graduação Stricto Sensu em Ciência Jurídica da UNIVALI, Itajaí, v.10, n.1, edição especial de 2015. Disponível em: www.univali.br/direitoepolitica - ISSN 1980-7791.

AMBIENTAL I: XXIII ENCONTRO NACIONAL DO CONPEDI. 1ed. Itajaí: Univali, 2014, v. 1, p. 23.

THERIVEL, Riki. Strategic Enviromental in Action. 2. ed. Washignton DC: earthscan, 2010.

Submetido em: Setembro/2014

Aprovado em: Outubro/2014 